\title{
Is a consensus possible on stem cell research? Moral and political obstacles
}

\section{W Brock}

\section{Neither of the two central moral and political obstacles to human embryonic stem cell research survives critical scrutiny}

$\mathrm{T}$ his paper argues that neither of the two central moral and political obstacles to human embryonic stem cell (HESC) research survives critical scrutiny: first, that derivation of HESCs requires the destruction of human embryos which are full human persons or are at least deserving of respect incompatible with their destruction; second, that creation of HESCs using somatic cell nuclear transfer (SCNT) or cloning is immoral. First, different sources of HESCs are distinguished and the distinct moral objections that might apply to each. Second, it is argued that none of the properties plausibly conferring personhood on an entity is possessed by human embryos, and then shown how destruction of an embryo for research with the prospect of important medical benefits can be compatible with respecting it. Third, it is shown that the main objection to human cloning is only to reproductive cloning and that the objection to creating human beings with the intention of destroying them does not apply to SCNT. Finally, the concern that acquiring human eggs for SCNT would involve exploiting women donors is addressed, and it is shown how that can be avoided.

Human embryonic stem cell (HESC) research has become one of the more politically and morally controversial issues of our time. There is wide variability in what HESC research, if any, is permitted in countries around the world. Within the United States HESC research was a major issue in the last presidential election and some states, such as California, are devoting substantial public monies to fund this research while others prohibit it. In this paper I will explore some of the main obstacles to reaching consensus on this issue in the hope of at least narrowing the disagreement and removing some of the obstacles to that consensus. I will take for granted the dominant view in the scientific community that this research has great scientific and medical promise for the understanding and treatment of a wide range of human diseases such as Type I diabetes and Parkinson's disease. It is this promise of important human benefits that comes into conflict with the moral and political obstacles to going forward with the research.

The first obstacle to consensus is that HESC research typically requires the destruction of human embryos in order to develop stem cell lines on which research can be done. This is an obstacle because many people believe that the deliberate destruction of human embryos is morally wrong. Some hold this view because they believe that human embryos are full human beings or human persons, entitled to all the moral protections of other born human beings. One of the most important of those protections is that against being killed. Others believe that although not a full human person, the human embryo is not morally equivalent to mere human tissue, is deserving of serious respect, and that it is incompatible with that respect to deliberately destroy the embryo. If one believes that the embryo is a human person, then it is correct to oppose HESC when it requires the destruction of an embryo. In general, it is wrong to deliberately kill someone for the benefit of others, and in particular, research is not permitted that will kill its subjects for the benefit of others. For some people, the belief that human embryos are full human persons is a religious dogma that does not rest on, and so is largely impervious to, rational argument; I do not expect that anything I say here will move those people toward any consensus permitting HESC research. The arguments that I shall present challenge this belief in its secular forms, as well as the weaker claim that while not a human person, the embryo deserves respect that is incompatible with deliberately destroying it.

The second obstacle to consensus is opposition to human cloning. Some HESC research involves so called therapeutic or research cloning, specifically somatic cell nuclear transfer (SCNT), which is used in the development of stem cell lines. Since it is possible to do HESC research without SCNT, it would be possible to bypass this source of opposition to it. There are, however, important scientific advantages to using SCNT in the development of stem cell lines for research. For the study of specific diseases such as Type I diabetes and Parkinson's disease that are thought to have a significant genetic component, SCNT allows the development of stem cell lines from the genetic material of persons who have those diseases. This in turn yields stem cell lines that allow the study of the development of these diseases. Surplus embryos left over from in vitro fertilisation (IVF) used for reproduction are unlikely to have this genetic make up.

Probably the main opposition to human cloning is to reproductive cloning, not research cloning. Thus, some have sought to respond to this second source of opposition to consensus on HESC research by arguing for a prohibition on reproductive cloning, while permitting research cloning. In response, opponents have employed so called slippery slope arguments to the effect that successful research cloning will inevitably lead to, or at least make more likely, reproductive cloning. I shall suggest reasons to doubt that this slope is slippery. As we shall see, however, there are other objections to research cloning, quite apart from any connection that it might have to reproductive cloning, and these must be met by supporters of SCNT for HESC research.

\section{THE SOURCES OF STEM CELLS}

There are various sources of stem cells for research and as these raise different moral objections to their derivation and use, they should be distinguished. The first source is already existing stem cell lines. In the United States, according to federal policy imposed by President Bush, the only stem cell lines eligible for federal funding are those already existing as of August 9, 2001 when the policy was announced. The rationale for this policy was that the life or death decision for the embryos used to develop these lines had already been made. Use of them does not require or provide any incentive for any further destruction of embryos. It is worth noting that for persons who believe embryos are either full human persons, or at least beings that deserve respect incompatible with their deliberate destruction, even this use may be ethically problematic. The ethical concern is complicity with the wrong of embryo destruction, although some have challenged the application of that concern here. ${ }^{1}$ Even if one cannot now undo the wrong of the embryo destruction, to make use of the results 
of that destruction could be seen to make one complicit in the wrongful destruction. This dilemma is comparable to that raised by the use of Nazi science resulting from their grossly inhumane scientific experiments. However bad the Nazis' science was in scientific terms, some believe that even if and when it did produce valuable scientific results they should not be published or used because doing so would make one complicit in the evil of the research. ${ }^{2}$ This complicity argument is controversial and will be rejected by consequentialists in the case of the Bush policy, but most opponents to HESC research are not consequentialists. Apart from the complicity concern, this is a relatively uncontroversial use of HESCs for research.

A second generally uncontroversial category of stem cells for research is the various sources that do not require the destruction of embryos. The most prominent example is adult stem cells that are derived from adult sources not involving embryos. There is scientific controversy about the relative scientific promise of adult stem cells, and most researchers believe they are likely to prove inferior to HESCs. ${ }^{35}$ The dominant view in the scientific community is that both embryonic and adult stem cell research should go forward until the promise of each becomes clearer. A second source is aborted fetuses, so long as the decisions about abortion and use of the fetus to derive stem cells are kept separate. This source again raises the complicity concern for some and in any case is not likely to produce sufficient material for the research. Other possible sources include stem cells derived from cord blood; unfertilised eggs leftover from IVF; embryos that have been genetically modified to lack the potential to develop beyond the blastocyst stage $^{67}$ and embryos that have been determined to be dead. ${ }^{8}$ For each of these alternatives, both scientific and ethical issues remain about their potential for stem cell research.

A third source of stem cells is those derived from embryos leftover from IVF for reproductive purposes. It is typical in this country for fertility clinics to fertilise a number of eggs for potential use in IVF since it is unclear at the outset how many will be needed in order to achieve a successful pregnancy. As a result, there are many excess embryos not needed for further reproductive use by the couples from whom they were derived that are now stored in freezers in IVF clinics; it is estimated that there are now about 400,000 such embryos in the United States. ${ }^{9}$ These embryos will either be frozen indefinitely or eventually destroyed, and so will never be implanted in a uterus and allowed to develop into a human being. Thus, there seems nothing lost by this use since these embryos will never be allowed to develop even if not used for stem cell research, and something gained, namely, moving forward this very promising scientific research. If one believes that human embryos are neither human persons nor beings deserving of respect that is incompatible with their destruction, then this reasoning provides strong support for use of surplus embryos for HESC research.

Should those who believe that embryos are either human persons or at least beings deserving of respect that is incompatible with their destruction accept that a "nothing is lost principle" justifies their use and destruction for research? I believe they should not. There are stronger and weaker versions of a "nothing is lost principle", and only the weaker and less plausible version applies to surplus embryos from IVF. Very roughly, the stronger version holds that we can kill a person who will die very soon anyway no matter what anyone does if doing so is necessary to produce a very great good such as saving other lives, as stem cell research might at least indirectly do. While still controversial, the ethical intuition at work here is that since the person will inevitably die very soon even if not killed, nothing is lost by doing so, whereas great gains to others can be realised. These surplus embryos from IVF will not inevitably die or be destroyed, however, no matter what anyone does; they will only be destroyed if someone makes the decision to destroy them, otherwise they will remain frozen indefinitely, retaining the biological potential to develop into human beings if implanted. So the stronger and more plausible version of the nothing is lost principle does not apply to them.

The weaker version of the principle looks to what will happen to the embryos given what others will in fact do, not given what anyone could do, and from that perspective nothing is lost because the embryos will in fact either be destroyed or remain frozen, and so will never be allowed to be implanted and to develop. The stronger version looks to whether the embryo retains the biological potential to develop, whereas the weaker version looks to whether in the actual social circumstances it will be allowed to develop. Those who believe that embryos are persons or deserve respect that is incompatible with killing them should not accept the application to surplus embryos of the weaker version as justifying embryos' use in HESC research. Doing so would be analogous to using an abandoned baby for research that would kill it because if one did not it would die anyway. The alternative of course is to care for the abandoned baby. Those who reject this weaker version of the nothing is lost principle will argue that the alternative with spare embryos is to keep them frozen or to give them to others for implantation. I emphasise that a nothing is lost principle fails to justify the use of surplus embryos for HESC research only on the assumption that embryos are human persons or beings deserving of respect that is incompatible with their destruction.

A fourth source of HESCs is embryos created by IVF specifically for the purpose of use in research to develop stem cell lines. These embryos will have been created by the same processes as embryos left over from IVF for reproductive purposes. The difference some see is that this creates and uses the embryos solely as a means for the benefit of others. These embryos are created with the explicit intent of destroying them in research, and unlike leftover embryos from IVF for reproduction, they would not have been created if they could not be later used and destroyed in research. I shall return to this objection later.

A final source of HESCs is the creation of embryos through cloning or SCNT. This raises the same "creation and use solely as a means" objection as did the previous source. It also raises the objection that some have to any form of human cloning. As already noted, some people opposed in principle only to reproductive cloning object to SCNT for research purposes on the ground that it will make reproductive cloning more likely-for example, by perfecting the process of SCNT.

I have reviewed the main sources of stem cells here in order to indicate how different ethical objections or concerns apply to those different sources. I shall take up many of those objections and concerns below, but it is important to be clear to which sources the various objections and concerns apply.

\section{EMBRYOS SHOULD NOT BE DESTROYED BECAUSE THEY ARE HUMAN PERSONS OR NASCENT HUMAN LIFE Implications}

The strong version of this objection holds that embryos are full human persons, no different morally from other born humans. Few who claim to hold this view accept its full implications, however, and this puts their acceptance of it in question. First, it is common practice to fertilise more eggs than will be used in IVF reproductive procedures, 
which results in many embryos later being destroyed. A defender of the "embryo is a person" view should reject this practice and indeed some do. Second, it is well known that for each embryo that is born alive from normal sexual reproduction, at least three are created who will die before birth. Thus, three embryos are sacrificed for each that is born. It would seem that a defender of the "embryo is a person" view should reject the practice of sexual reproduction as well because of the great loss of innocent human life that it involves. Third, the loss of embryos in either of the above circumstances is rarely grieved over in the way the death of a person, or even a fetus, is grieved over. Fourth, in Michael Sandel's example, if there was a fire in the fertility lab and one could save a tray of 100 surplus embryos or one eight year old child, but not both, virtually everyone would save the child. ${ }^{10}$ However, virtually everyone would save a hundred children instead of one other child if one could not save all. These various examples, and others, suggest that people do not view embryos as morally comparable to born human beings or persons. It is a minimal requirement for anyone's moral views to be justified that they be internally consistent, but each of these examples represents apparent inconsistencies in the views of most who hold that the embryo is a person. Perhaps some will accept these and other implications of their view, but I doubt it.

\section{EMBRYOS ARE "ONE OF US," NASCENT HUMAN LIFE}

Both the President's Council of Bioethics, as well as some of its members in their writings, have put their position regarding the embryo in terms of its being "one of us," a member of the human family. An embryo is nascent human life that in the course of normal development will become a born human being, just as each born human being started life as an embryo. ${ }^{11}$ These claims could be challenged on the basis of the assumptions about personal identity they embody, but even setting those issues aside they do not yield the conclusions their proponents want to draw from them. ${ }^{12}$ It is certainly correct that a human embryo is a member of the human species, not a member of some other species such as frogs or cows, but that is not sufficient to give it the same moral status as humans who are incontestably persons. That is because the moral status of human persons does not derive simply from their species membership. Rather, it must be some properties of humans that endow them with personhood and in particular make it seriously wrong to kill them. If it is mere species membership that is thought to endow humans with this special moral status, that would be akin to racists' or sexists' claims of special moral status or superiority for their own race or sex, without offering any basis for the claimed superiority.

What that further basis is that grounds the personhood and moral status of humans is controversialsentience, consciousness, self consciousness, and capacity for purposive behaviour are among the candidates that have had their advocates. ${ }^{13}$ But whatever the property(s) is that is thought to confer personhood, organisms or beings that lack it are not persons. The important point about embryos at the blastocyst stage at which they are destroyed in the process of developing stem cell lines is that they clearly lack any of the properties that have been, or might plausibly be, claimed to confer personhood. At the blastocyst stage the embryo is a 100-200 cell undifferentiated organism, no larger than a period on this page, with no organ system, brain, or any of the other properties typically thought to confer personhood.

The importance of this further ground beyond mere species membership for personhood can be illustrated with two fanciful examples. First, suppose that an environmental disaster led to some women giving birth to organisms that appeared to be identical to baby kittens and that grew and developed as cats. By the usual criteria of species membership, roughly the offspring of humans, these would be humans. But they would not, nor should they properly be, treated as humans with the moral status of normal humans. Instead, they would properly be treated as cats. Second, suppose that another environmental disaster led to some women's embryos never developing beyond the 100-200 cell blastocyst stage, but they could be extracted at that time and kept alive or frozen in a laboratory. Would there be any reason to assign them full moral status or personhood and to protect their lives? If not, that suggests that it could only be the potential of normal human embryos to develop into full human beings that could give the embryo its moral status, an issue I shall take up next.

\section{POTENTIALITY}

Some would ground embryos' moral status as persons not on any present capacity they have, but rather on their potential to develop, be born, and become normal humans. Potential is clearly relevant to the economic value of a thing-if a young pony has the potential to develop into a horse that can run faster than any other horse, its economic value as a racehorse is much greater than another pony that lacks that potential. Likewise, potential is relevant to the instrumental value of something in achieving a desired end. Organs that can be used for transplantation have more instrumental value than organs that are unusable for transplantation. The economic and instrumental value of an entity or thing is the value it has for some purpose or for others, not its intrinsic value. The relevant question for potential's impact on the moral status of an embryo is whether the fact that an embryo has the potential to develop into a human person, even though while still an embryo it is not a human person, is sufficient to confer on the embryo the moral status it will later have after it becomes a human person. If Sarah, who has a terminal illness, writes her will leaving her house to her daughter, then her daughter is potentially the inheritor of the house with the right as inheritor then to sell the house to others. But until she is the inheritor, not just potentially the inheritor, she has no right to sell the house. If Sam has the potential to run faster than all the other competitors in the race, then he has the potential to claim the prize, but he has no actual claim or right to the prize until this potential becomes actuality and he has in fact run faster than all the other competitors. Moral rights in general have this character-they are grounded in the actual, not just potential, properties of a being. So the embryo's potential to become a person is relevant to the moral status it will have if and when it does become a person, but it does not confer the moral status on it when still an embryo that it will have later when it has become a person.

In the case of embryos produced by cloning or SCNT, some scientists believe these human embryos have little if any potential or probability of developing to the point that they could be born alive, certainly born alive and healthy. ${ }^{14}$ That is consistent with the experience of attempting to clone some animals, whose developmental complexity and demands are much less than those of humans. If these scientists are correct, then it is a mistake to ascribe to cloned human embryos even any significant potential to become a born human, whatever the moral significance of such potential might be. And if cloned human embryos lack any significant potential to develop and be born alive, then the putative slippery slope from research to reproductive cloning feared by opponents of the latter is not slippery at all; the former cannot lead to the latter. 


\section{THE CONTINUITY OF DEVELOPMENT}

Guidelines developed for the use of embryos in the development of stem cell lines have generally included a limit of 14 days, or alternately the development of the primitive streak (these are roughly the same in time), beyond which the blastocyst cannot be kept alive and used for research. This means that the blastocyst can be used for research purposes up until 14 days, but not after that time. Presumably it should be some change in the nature of the blastocyst at that time that changes its moral status and makes it a being that can no longer be ethically used for research. It has been argued, however, that human development from conception to birth is continuous and there is no non-arbitrary point at which we can say that the embryo or fetus has acquired moral status whereas before that point it lacked it. ${ }^{15}$ If the 14 day limit is in this sense arbitrary, the argument goes, we should assign it full moral status from the beginning of its development (The President's Council on Bioethics, ${ }^{11}$ p 154).

There is more than one error in this argument, but it should be sufficient to point out a central one. Let us grant that there is no difference in the nature of an embryo at 13 days' as opposed to 15 days' development that justifies setting the limit on its use for research at precisely 14 days. Likewise, there is no justification for setting the age at which citizens acquire the right to vote at precisely 18 years. The development of the cognitive and other capacities relevant to having a right to vote is also continuous, varies from individual to individual, and there is no marked change in those capacities just at the 18th birthday. Nevertheless, there is no controversy that-for example, at age five these children's relevant capacities have not developed to a point at which they should receive the right to vote; there is nothing arbitrary about denying the right to vote to five year olds. So also in the case of embryo use, even granting that the 14 day limit does not precisely mark any change in embryo development of great moral import, it may be early enough to be sure that the embryo at this blastocyst stage still lacks any properties that could plausibly confer a moral status on it that would make it seriously wrong to kill it. The 18 year age line assures that most will have acquired sufficient capacities to exercise the right to vote, even though some might hold that those capacities are generally or often acquired earlier, and the 14 day line assures that the embryo has not yet acquired the properties to make it a person, even if at later stages of development it also might still not have acquired those properties or that moral status.

I believe we can conclude that secular moral arguments fail to persuasively establish that human embryos are full human persons who should never be deliberately destroyed.

\section{EVEN IF THEY ARE NOT HUMAN PERSONS, EMBRYOS ARE NOT MERE TISSUE AND ARE OWED SPECIAL RESPECT}

Many people who do not believe that a human embryo is a full human person nevertheless believe it is not like mere human tissue, to be destroyed or discarded at will. Instead, it is a morally significant entity deserving of serious moral respect (The President's Council on Bioethics, ${ }^{11}$ p 138-9). In this view human embryos have some form of intermediate moral status between full human persons and morally insignificant entities or things. (My own view is that that moral status is minimal, but I want to pursue the implications of assigning the embryo more significant moral status.) In particular, is it compatible with respecting the human embryo to destroy it in the service of the development of stem cell lines? In stating the case against cloning for stem cell research, The President's Council on Bioethics stated that: "it is incoherent and self contradictory...to claim that embryos deserve "special respect" and to endorse none the less research that requires the creation, use, and destruction of these organisms" (The President's Council on Bioethics, ${ }^{11} \mathrm{p}$ 154). It is correct that it is certainly not the typical way that we show respect for either a thing, such as a statute, or an organism, such as an animal or a person, to destroy it. Nevertheless, I believe that it is a mistake to believe that intermediate moral status requiring special respect is incompatible with creation, use, and destruction of embryos in research. Consider another type of entity to which many persons assign intermediate moral status-animals such as monkeys or dogs. These animals are not mere things to be used for human purposes in any way we wish; their capacity to suffer, at a minimum, undergirds their intermediate moral status. Yet these animals are bred, used, and sometimes killed or destroyed in the course of biomedical research aimed at understanding and treating serious human disease. Many people accept that practice as morally permissible and compatible with the animals' significant, but intermediate, moral status. Yet those same people typically oppose the breeding, use, and destruction of such animals for cos- metics research. What is the difference? It is clearly and only the seriousness or importance of the purposes of the two activities. It is incompatible with these animals' intermediate moral status and the special respect they are owed to create, use, and destroy them for a relatively trivial human purpose such as developing cosmetics. Limiting their creation, use, and destruction only to research aimed at understanding and treating or preventing serious human disease is a way of showing them special respect and recognising that their intermediate moral status implies that they cannot be used for just any human purpose.

Likewise, human embryos could be shown the special respect that intermediate moral status requires by limiting their use to equally important human purposes. That special respect would justify guidelines limiting embryos' use and destruction to research with reasonable promise of alleviating serious human disease and suffering, together with procedures to ensure that those guidelines were followed. There is little controversy about whether HESC research has that promise, despite uncertainty about how quickly that promise is likely to be realised. Currently, institutional review board (IRB) review is generally required only for egg, sperm, or cell donation, or when the donors for stem cell lines are identifiable. Thus, if a public policy decision was made to recognise that human embryos have intermediate moral status requiring special respect, further guidelines and regulation would be appropriate.

We can now draw the further conclusion that even if human embryos have intermediate moral status requiring special respect, that is not incompatible with creating, using, and destroying them for medical research that has a reasonable promise to understand, treat, or prevent serious human disease.

\section{PROCURING EMBRYOS BY SCNT - THE CLONING OBSTACLE}

As I noted at the outset, the use of human cloning is a second major obstacle to reaching moral and political consensus about HESC research. But the core of opposition to human cloning is to reproductive, not therapeutic or research, cloning. If it is correct that cloned human embryos have little if any chance of developing to be born alive and healthy, then the concern that if SCNT is used to develop HESCs that will increase the likelihood of reproductive cloning is a misplaced concern. Nevertheless, use of SCNT to produce HESC lines does raise another objection that deserves to be addressed. 
This objection also applies to the use of IVF without any reproductive intent and solely to create embryos to produce HESC lines, so it is not an objection to therapeutic cloning in itself. However, it has been principally addressed to the use of SCNT because that is the most likely source of embryos created explicitly for use in research to produce HESCs. The objection is that to create embryos with the sole intention of using them in research in ways that will lead to their destruction is to treat them instrumentally, merely as a means to others' benefit. Doing so has been held to violate the Kantian injunction to treat human life as an end in itself, never solely as a means. ${ }^{16}$ Analogously, we would certainly not permit the creation of persons, by SCNT, IVF, or normal sexual reproduction, who were to be used in lethal experiments or as a source of vital organs at age two for the benefit of others. However, this objection mischaracterises the Kantian injunction. As Kant formulated it, it was an injunction against using "rational beings" solely as means for the benefit of others. It applies to rational beings because they are agents who have ends and purposes of their own that cannot be justly disregarded in their treatment. Live human tissue-for example, that left over from medical procedures, on the other hand, can justly be treated solely as a means or instrumentally because it has no interests or rights that can be violated by that use. This means that a central issue for this objection is whether an embryo at the blastocyst stage is the kind of entity that has purposes, interests or rights that would be violated by its use solely as a means.

I have already argued above that mere species membership cannot confer moral status or rights on an embryo and that an embryo at the blastocyst stage lacks any of the properties that could plausibly be thought to confer such status. Likewise, it lacks any of the properties that would make it a rational agent with interests or purposes of its own to which the Kantian injunction would apply. Indeed, even if one grants that an embryo deserves special moral respect, presumably because of its potential to develop into a human person, I argued above that that respect is compatible with its creation, use, and destruction for HESC research. If it is permissible to use embryos in research in the course of which they are destroyed, then it should be permissible as well to create them for that purpose, just as it is permissible to create animals for use and destruction in research. If the value of the use to which they are put and the nature of embryos at the blastocyst stage make their use and destruction in research permissible, then creating embryos for this permissible use should be permissible. If the concern is with the possible commercialisation or commodification of embryos-for example, their purchase and sale, that can be separately prohibited by law without prohibiting their use in stem cell research.

A different ethical objection to SCNT is that it is asexual reproduction, unlike assisted sexual reproduction such as IVF, and is a first step toward taking control over shaping the nature of our offspring, toward engineering humans. This is another version of the slippery slope argument against SCNT, but the worry is that the slope will lead to excessive control over the nature of our offspring, not to reproductive cloning in itself. What kinds of control over the nature of our offspring might be ethically objectionable is too large an issue to address here, although I have addressed it elsewhere. ${ }^{17}$ This slippery slope argument assumes that that control is wrong, but the force of slippery slope arguments depends on our inability or unwillingness to distinguish the one practice from others to which it supposedly will lead. Somatic cell nuclear transfer for research purposes does not in any way amount to controlling the nature of our offspring because it does not lead to reproduction at all. So it is hard to see why it is likely to promote practices that involve that control. The motives underlying SCNT for research purposes are unconnected to any motives concerning reproduction in general or controlling the nature of our offspring in particular. Since practices that do aim to control the nature of our offspring, such as genetic testing in the reproductive context, preimplantation genetic diagnosis, or genetic manipulation of an embryo, are all quite distinct from SCNT for research, they can be separately regulated if society chooses to do so.

\section{THE IMPLICATIONS OF PUBLIC POLICY ON IVF FOR HESC RESEARCH}

In IVF for reproductive purposes, public and legal policy grant authority to a woman and man over the embryo created from their egg or sperm. They have the authority to choose to have it implanted, to donate it to others, to have it frozen and stored, or to have it destroyed. Given the embryo's minimal moral status just after fertilisation, that is in my view the correct public policy. It is hard to see why anyone else has a stronger claim to that authority over the disposition of the embryo instead. If the woman and man whose embryo it is can destroy the embryo or donate it to another woman to use for reproduction, then why cannot they donate the embryo to researchers who will destroy it in using it for research? They transfer their right to control the disposition of the embryo to the researchers, who thereby acquire the comparable right to use it for the purpose for which it was donated.

An embryo's moral status is grounded in the nature of the being that it is, not on how it is created. The more than one million individuals who have been created by IVF have the same moral status as individuals created by normal sexual reproduction. If embryos have an intermediate moral status deserving of respect that is compatible with their destruction when they become surplus and are no longer needed for reproduction, then they may likewise be used and destroyed for the important human purpose of treating or preventing serious human disease, suffering, and loss of life. Even granting for the sake of argument that embryos created by SCNT are similar in their nature to those created by IVF, it should likewise be compatible with respecting them to use and destroy them for important medical research. If, on the other hand, embryos created by SCNT lack the potential of embryos created by IVF to develop to term, then if anything this reduces their moral status, presumably making their use in research more easily justified.

\section{AVOIDING EXPLOITATION OF WOMEN IN EGG PROCUREMENT}

There is a third potential obstacle to consensus about HESC research, although it has received much less attention than the first two, and that is the possible exploitation of women in egg procurement. Human eggs for creating embryos either by IVF or by SCNT must be donated by women. The process typically involves use of hormones to stimulate egg production and an invasive procedure to retrieve the eggs. The number of eggs that will be needed in the future is difficult to predict, but if the research continues to prove promising, the numbers are likely to increase. If stem cell therapy, as opposed to research, becomes possible at some future time the number of eggs needed may increase very substantially. In future stem cell therapy, eggs may often be obtained from family members of the patient, but that will not always be possible. Thus, often eggs will have to be obtained from an egg donor, either for research or for patients with no relationship to the egg donor. Proper informed consent from the egg donor must always be obtained, and this is required by law. 
The information provided to the donor should include statements that:

the embryo will be used for derivation of HESCs and, if and when appropriate, that cells may be used for transplantation;

the donation is made with no restrictions to specific area of research or, when and if appropriate, without specification of transplant recipient, whether or not any identifiable information will be attached or linked to the HESCs and, if so, how confidentiality will be maintained;

derived HESCs will be kept for many years;

there may be commercial potential and there are no plans for the donor to receive any such benefits;

there is no direct benefit to the donor; embryos will not be transferred to a uterus;

embryos will not survive the HESC derivation process, and

the derivation process was approved by an IRB.

These requirements for informed consent essentially follow the Clinton administration guidelines. ${ }^{18}$

Valid informed consent also requires that the donor's decision to donate her eggs be fully voluntary. It is here that concerns about possible exploitation arise. The principal worry is that if very large compensation is offered to donors this might render their decision to donate coerced, or at least subject to undue influence, particularly in the case of very poor donors whose need for money is pressing or even desperate. There is controversy about whether such offers, as opposed to threats, can be coercive, but at the least it is ethically desirable that donors not principally be desperately poor women without other sources of income. ${ }^{19}$ As in other research, the typical means of avoiding this worry is to limit the compensation offered to participants, in this case donors, to reasonable reimbursement for their time and expenses. Exactly how much this would be could be up to individual IRBs to determine. Further regulations are possible to limit concerns about exploitation, such as registering all donors for HESC research and limiting multiple cycles for donation. With reasonable limits to financial compensation and possibly other regulations, donors are likely to be individuals with concern either for medical research generally, or for the diseases for which stem cell research is especially promising.

In the case of surplus embryos left over from IVF undertaken for reproductive purposes, it is reasonable to preclude any compensation for embryo donation. First, women will be under- taking no significant additional time or health burdens by making their surplus embryos available for research, which is the rationale for compensating egg donors. Second, doing so responds to the concerns of many about commercialisation or commodification of human embryos. The motives of women donating surplus embryos from the use of IVF undertaken for reproduction would almost certainly be to do with concern to further stem cell research or therapy. There seems no reason for serious concern about exploitation in this case. The same reasoning applies to cases in which women undergoing fertility treatment and IVF deliberately have more eggs fertilised than they expect to use for reproduction in order to have some available to donate for research.

In the case of egg donation for the creation of embryos explicitly for research use either by IVF without any reproductive intent or by SCNT, women's motivations for donating could be primarily for financial compensation if substantial financial compensation were permitted. As already noted, this could lead to exploitation of poor women and could and should be prevented by limiting financial compensation to time and expenses. Those opposed to any form of commercialisation or commodification of the human embryo will likely want to prohibit any compensation to these embryo donors even for their time and expenses, but their opposition to compensation would be to prevent commodification of embryos, not to prevent exploitation of the women donating their eggs. If compensation is appropriately limited, the primary motivation of women donating their eggs in the absence of any reproductive intent will be to further stem cell research and/or therapy. No doubt they will often be individuals with close friends or family members affected by diseases for which stem cell research is thought promising, or for which, in the future, there may be stem cell therapies. Their motivations will be primarily altruistic and using eggs they wish to donate should not involve any significant exploitation. The concern about exploitation of egg or embryo donors does not appear to be an insuperable ethical obstacle to proceeding with the research or later possible therapy.

Even if there would be no exploitation of egg donors because of appropriate limits on their compensation, it might still be thought that they would be undertaking excessive risks in the absence of any medical benefits to them. The process of hormonal stimulation and egg retrieval is certainly not without risks to women, but at least when it is done for reproductive purposes there are direct expected benefits to the women involved. Should women not be permitted to undertake those risks in the absence of reproductive intent and solely to further stem cell research or therapy? So long as donors' decisions are free and informed, I believe it would be unduly paternalistic to prohibit them from undertaking these risks of egg donation for research or therapy for the benefit others. It would also be inconsistent with practice in other areas of medicine, research, and ordinary life. Perhaps the most obvious example is the donation of kidneys by living donors to unrelated recipients, an increasingly common source of kidneys for transplantation. This practice is widely accepted and involves significantly greater risks to the donors than does egg donation. In many other contexts we admire those who undertake even quite substantial risks or hardships for the sake of others suffering from natural disasters, the effects of war or poverty, and other emergencies or hardships; we do not try to prevent them from freely and knowingly choosing to try to help others at some risk to themselves. Likewise, we should admire these egg donors and respect their choice to donate to help others, not seek to prevent them from doing so.

\section{CONCLUSION}

The various arguments that I have offered here in support of HESC research will not convince those who accord the human embryo full moral status as a matter of religious dogma. Since many persons do exactly this, we should not expect anything like full consensus on the issues; their belief is not subject to change by arguments of the sort I have offered here. From a political perspective, it is fortunate that such individuals are almost certainly not a majority of the United States population. Moreover, public policy that binds all citizens should not be based on reasons whose force depends on the acceptance of a particular religious doctrine that many citizens reasonably reject. Polls have consistently shown that a majority of Americans support stem cell research, and the recent California referendum showed a substantial majority in support of using state tax monies in support of the research. Other states are now considering similar measures. For other individuals who consider the embryo less than a full human person, my hope is that the arguments that I have offered here could serve as a basis for broadening support for the ethical acceptability of HESC research. 
J Med Ethics 2006;32:36-42.

doi: 10.1136/jme.2005.013581

Correspondence to: D W Brock, Division of Medical Ethics, Department of Social Medicine, Harvard Medical School, 641 Huntington Avenue, 4th Floor, Boston, MA 02115 ; dan_brock@hms.harvard.edu

Received 27 July 2005

Accepted for publication 2 August 2005

\section{REFERENCES}

1 Robertson J. Causative versus beneficial complicity in the embryonic stem cell debate. Conn Law Rev 2004;36:1099.

2 Rosenbaum AS. The use of Nazi medical experimentation data: memorial or betrayal? Int J Appl Philos 1989;4:59-67.

3 Wagers AJ, Sherwood RI, Christensen JL, et al. Little evidence for developmental plasticity of adult hematopoietic stem cells. Science. 2002;297: 2256-9, 5590.

4 Prentice DA. Appendix k. Adult stem cells. In: The President's Council on Bioethics, ed. Monitoring stem cell research. Washington DC, US Government Printing Office, 2004.

5 Verfaillie CM. Multipotent adult stem cells: an update. In: The President's Council on Bioethics, ed. Monitoring stem cell research. Washington DC: US Government Printing Office, 2004.

6 Cook G. New technique eyed in stem cell debate. Boston Globe, 2004 Nov 21.

7 Melton DA, Daley GQ, Jennings CG. Altered nuclear transfer in stem cell research-a flawed proposal. N Engl J Med 351, 27:2791

8 Landry DW, Zucker HA. Embryonic death and the creation of human embryonic stem cells. Journal of Clinical Research 2004;114:1184-6.

9 Weiss R. 400,000 embryos frozen in US. Washington Post. 2003 May 8: A 10

10 Sandel $M$

11 The President's Council on Bioethics. Human cloning and human dignity: an ethical inquiry.
Washington DC: US Government Printing Office, 2002

12 De Grazia D. Human identity and bioethics. Cambridge: Cambridge University Press, 2005.

13 Warren MA. Moral status. Oxford: Oxford University Press, 1997.

14 Jaenisch R. Human cloning-the science and ethics of nuclear transplantation. N Engl J Med, 27:2787-91.

15 The President's Council on Bioethics. Monitoring stem cell research. Washington DC: US Government Printing Office, 2004

16 Kant I. Groundwork of the metaphysics of morals. Cambridge: Cambridge University Press, 1998.

17 Brock DW. Is selection of children wrong? In Savulescu J, ed. The enhancement of human beings. Oxford: Oxford University Press (in press).

18 National Institutes of Health. National Institutes of Health guidelines for research using human pluripotent stem cells. 65 Fed Reg 51,975: 200 Aug 25.

19 Wertheimer A. Coercion. Princeton, NJ: Princeton University Press, 1988. 